IJES

5,1

18

Received 11 November 2015 Revised 2 February 2016 21 February 2016 Accepted 1 March 2016

\section{The nexus of transformational leadership of emergency services systems}

\section{Beyond the Wu-Shi-Ren (WSR)-Li paradigm}

\author{
Denis Caro \\ Telfer School of Management, University of Ottawa, Ottawa, Canada
}

\begin{abstract}
Purpose - In the face of diverse national and international threats, the purpose of this paper is to explore the transformational leadership challenges in emergency services systems in Canada. These adaptive complex systems respond to critical mass emergencies, disasters and catastrophes.

Design/methodology/approach - This qualitative research study uses grounded theory to examine the phenomenology of emergency services leadership from systems perspective. Using the theoretical Wu-Shi-Ren (WSR)-Li systems paradigm, this key informant study of 103 emergency leaders from 81 organizations focusses on the systemic challenges that transformational leaders face in emergency services systems. The response rate was 83.5 percent using a semi-structured and open-ended questionnaire.

Findings - This key informant study underscores the competencies for transformational leadership and identifies 12 key leadership challenges in the context of the future evolution of emergency services systems. From the use of a grounded theory methodology, the new theory of transcendental transformational emergency leadership is posited.

Research limitations/implications - Qualitative studies such as this key informant study underscores the relevance of the WSR-Li systems paradigm and grounded theory approach in discerning leadership challenges that are specific if not unique to emergency services systems.

Practical implications - This study underscores the theoretical and pragmatic implications of the transformational leadership challenges for leadership paradigms, innovation and inter-sectorial collaborative networks and possible future emergency services research.

Social implications - This study stresses the importance of addressing leadership challenges of emergency services systems as instrumental in ultimately saving lives, minimizing injuries and assuring complete health and social recovery from the scourges of emergency events nationally and internationally.

Originality/value - Qualitative studies of the perspectives of strategic emergency leadership of systemic emergency services systems has not hitherto been done in Canada nor internationally. This key informant study underscores the relevance of the WSR-Li systems paradigm and grounded theory approach in discerning transformational leadership challenges that are specific if not unique to emergency services systems. Moreover, from the use of a grounded theory approach, a new theory of transcendental transformational emergency leadership emerged.
\end{abstract}

Keywords Transformational leadership, Qualitative research, Emergency services systems, Key informants, WSR-Li systems model

Paper type Research paper

(C) Caro. Published by Emerald Group Publishing Limited. This article is published under the Creative Commons Attribution (CC BY 3.0) licence. Anyone may reproduce, distribute, translate and create derivative works of this article (for both commercial and non-commercial purposes), subject to full attribution to the original publication and authors. The full terms of this licence may be seen at: http://creativecommons.org/licences/by/3.0/legalcode
International Journal of Emergency Services

Vol. 5 No. 1, 2016

pp. $18-33$

Emerald Group Publishing Limited 2047-0894

DOI 10.1108/IJES-11-2015-0024 


\section{Introduction}

This study examines the results and implications of a key informant study of strategic leadership challenges faced in emergency services systems in Canada. It uses a grounded theory methodological approach to examine the phenomenology of emergency leadership to elucidate systemic challenges through a Wu-Shi-Ren (WSR)-Li paradigm. The results of key informant perceptions of emergency leadership attributes and competencies are presented, as well as 12 perceived leadership challenges. A theory of transcendent transformational emergency leadership is posited as an outcome of the grounded theory approach. The research and theoretical implications for emergency services systems are suggested and explored.

\subsection{Background}

The literature on leadership is constantly evolving as research continues on the dynamics of socio-behavioral complexities in a myriad of organizational contexts. In the epistemology of leadership, research studies identify a typology of styles. Authentic leadership focusses on the value attributes that wins legitimacy through ethical behaviors, integrity, openness and truthfulness (Quinn et al., 2007; Avolio and Gardner, 2005; Bass and Steidlmeier, 1999). Transformational leadership underscores the ability to lead and change organizational cultures by inspiring others and innovating (Phipps and Prieto, 2011). Authentic transformational leadership that merges elements of both authentic and transformational leadership (Bass and Bass, 2009). Here leadership influences, inspires and motivates, while retaining altruistic intents and actions based on ethical integrity (Price, 2003). There is a growing recognition of the importance of the socio-cultural context of leadership (Osborna and Marion, 2009). Adaptive leadership is goal-directed and evolves purposefully over time (Obolensky, 2014). Recently, the literature reports on integral leadership, which is a holistic epistemological approach that integrates the notions of authentic, transformational, adaptive and contextual leadership (Larsson and Eid, 2012; Wilber, 2000). The integral approach views leadership as a nexus of individual actions, collective behaviors and system processes in dynamic and evolving socio-cultural contexts.

In terms of emergency leadership, the literature reports on operational leadership in incident command systems (Rimstad and Sollid, 2015; Launder and Perry, 2014; Hayes and Omodei, 2011). Recently, recent literature has given special attention on the importance of emergency leadership in organizational resilience (Hills, 2015; De Florio, 2014; Moe, 2012), as well as contextual aspects of leadership (Charman, 2015; Larsson and Hyllengren, 2013). Yet, there appears to be a paucity of literature that examines emergency leadership challenges from a strategic systems perspective (Caro, 2015; Karaca et al., 2012). This paper hopes to contribute to this body of knowledge by reporting on and exploring the salient findings of a national study of strategic leadership challenges of emergency management systems in a Canadian context. It does so from a unique perspective that engages a Sino-perspective of systems, more specifically using Zhu's WSR-Li paradigm of systems evolution (Zhu, 2002; Zhu, 2001). Although one of many, this ontological paradigm is posited to be relevant if one views emergency services as complex and dynamic adaptive systems (Ma and Osula, 2011) that are constantly evolving.

\subsection{Emergency services as complex adaptive systems}

The underlying perspective in this study is that emergency services operate as dynamic systems that are horizontally and vertically linked. The horizontal dimension is a continuum of care that include prehospital care; transportation; emergency unit care; 
IJES

5,1

specialized tertiary care services; and recovery and rehabilitation. The vertical dimension involves emergency service organizations, institutions, regional authorities, national governments and international organizations. The premise in this study is that horizontally and vertically integrated systems are desirable to save lives and reduce injuries and protect the integrity and viability of communities. In normative times, emergency services systems tend to be function as silos that are loosely linked with professionals and institutions focussed primarily on internal care processes. In mass emergencies, disasters and catastrophes, the need for close system integration suddenly becomes compelling and essential in the struggle of life and death on a large scale. The premise of this study is that strategic emergency leadership is the lynchpin that integrates the system both in normative and chaotic situations. It is the critical ingredient that draws disparate and diverse systemic resources together and focusses and channels them into effective responses to external emergency events. It is also assumed that strategic leadership seeks to improve the efficiency and effectiveness of emergency services through systemic horizontal and vertical integration. In so doing, leaders encounter systemic challenges. This study seeks to elucidate what these strategic leadership challenges are from the perspective of emergency leaders. In turn, these challenges shed light on potential leadership directions in the evolution of future emergency services systems.

\subsection{The WSR-Li theoretical framework}

The WSR-Li paradigm espoused by Zhu (2001) provides one potent paradigm to help understand the Realpolitik dynamics and evolving role of strategic leadership of emergency services systems. Essentially, this systems model maintains that individual psycho-cognitive elements (shili) and collective socio-political processes (renli) that allocate systemic resources (wuli) are in continuous interplay. From Zhu's (2002) perspective , "sensing and caring" transform the "knowing" and the "doing."

The main components of Zhu's model, as articulated in the domain of emergency services systems, is summarized in Table I and include:

(1) transactional capital, the "wuli" dimension, pertains to the wide spectrum of systemic resources, such as care providers, financial resources, information and emergency supply resources;

(2) relational capital, the "shili" dimension, pertains to individual psycho-cognitive elements, such as perceptions and values based on mutual professional respect, trust and understanding that bring emergency care providers and professionals together;

(3) transactional processes, the "renli" dimension, pertains to operational sociopolitical processes, such the flow and exchange of care providers, financial resources, information and supplies throughout emergency systems; and

(4) transformational processes, also a "renli" dimension, pertains to strategic sociopolitical processes, such as emergency leadership that transforms systems and influences its growth and evolution.

In the context of this paradigm, one may postulate that emergency leaders interact to build and exchange relational capital (shili) in the form of trust, respect and understanding. In so doing, they benefit from exchanges and transfers of care providers, financial resources, information and emergency resources (wuli). This is done through operational transactional processes (renli). Strategic leadership direct and influence the evolution of the system through transformational processes (renli). 


\begin{tabular}{|c|c|c|c|}
\hline Dimensions & Focus & Emergency services systems articulation & 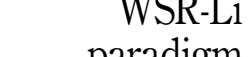 \\
\hline 1. Transactional resources (wuli) & $\begin{array}{l}\text { "Knowing" } \\
\text { Operational resources } \\
\text { Information } \\
\text { Knowledge }\end{array}$ & Resourcing systems & \\
\hline \multirow[t]{2}{*}{ 2. Relational capital (shili) ${ }^{\mathrm{a}}$} & & $\begin{array}{l}\text { Authentic leadership } \\
\text { Building mutual trust }\end{array}$ & \multirow[t]{2}{*}{21} \\
\hline & $\begin{array}{l}\text { Psycho-cognitive } \\
\text { values } \\
\text { Weltanschauung }\end{array}$ & Shared caring values & \\
\hline 3. Transactional processes (renli) ${ }^{\mathrm{a}}$ & $\begin{array}{l}\text { "Doing" } \\
\text { Operational } \\
\text { management }\end{array}$ & $\begin{array}{l}\text { Systems integration } \\
\text { Harmonization }\end{array}$ & Table I. \\
\hline $\begin{array}{l}\text { 4. Transformational processes } \\
{\left(\text { renli) }^{\mathrm{a}}\right.}^{\text {5. Transcendental forces }}\end{array}$ & $\begin{array}{l}\text { "Transforming" } \\
\text { Strategic management } \\
\text { "Leveraging" } \\
\text { Governance }\end{array}$ & $\begin{array}{l}\text { Transformational leadership } \\
\text { Governance leadership } \\
\text { Intersectorial leadership }\end{array}$ & $\begin{array}{r}\text { Summary of } \\
\text { WSR-Li } \mathrm{L}^{\mathrm{a}} \text { model } \\
\text { dimensions in } \\
\text { the context of } \\
\text { emergency services }\end{array}$ \\
\hline Note: ${ }^{\mathrm{a}} \mathrm{Zhu}(2001,2002)$ & & & systems \\
\hline
\end{tabular}

\subsection{Study goals}

The central goals of this key informant study are threefold: to identify the perceived attributes and competencies of emergency leadership deemed important; to explore the perceived leadership challenges in emergency services systems; and finally to posit a new theoretical paradigm that emerges from a grounded theory approach. The theoretical deployment of Zhu's WSR-Li paradigm in this study is postulated to be relevant and reflective of the complex adaptive nature of emergency services systems. Moreover, although there are diverse potential systemic models, this unique paradigm proved of benefit in elucidating the key systemic challenges faced by emergency leaders. Moreover, this study deploys thematic analysis and grounded theory approaches with the conceptual space of the generic WSR-Li model, proposed by Zhu (2002). The theoretical and analytical results produced an integrated systemic paradigm that sheds light on multidimensional transformational emergency leadership. The emergent theoretical construct is the theory of transcendent transformational emergency leadership.

\section{Methods}

Until recently, the extant literature has not reported on qualitative research studies on the perception of emergency leaders of systemic challenges faced in Canada. This qualitative study explores the phenomenology of emergency leadership, using a grounded theory and key informant approach to elicit the perspectives of emergency leaders of these challenges. Grounded theory is an inductive methodology and a systematic process of generating theory from conceptual categories and emerging thematic analysis (Charmas, 2014) and has been deployed in other studies (Burstrom et al., 2013; Seidel and Urquhart, 2013). Moreover, this study deploys a triangulation approach, whereby conceptual leadership and complex adaptive systems constructs are merged with the WSR-Li model to form the theoretical framework. A key informant survey questionnaire was deployed as the prime research instrument to collect qualitative information from emergency leaders 
IJES

5,1

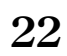

and has been used in other settings (Hopia and Hakala, 2015; Leggio, 2014). This key informant study underscores the key strategic challenges faced by leaders of emergency services systems.

\subsection{Study design}

Given that this was a qualitative study of human subjects, an institutional research ethics board reviewed and then approved the study objectives, protocol and research instrument. Select professional bodies were points of entry that consented to issue invitations to their membership to participate in this study. These included the Canadian Association of Fire Chiefs, the Canadian Association of Social Workers, the Canadian College of Health Leaders and the Canadian Information Processing Society. This chain referral sampling approach facilitated access to diverse public safety and emergency leaders across a wide spectrum of emergency services systems in Canada. There was a six-week response time limit that defined the purposive sample size consonant with the study objectives. The key informant recruitment strategy was voluntary and confidential, as were the responses. Within the defined time limit of the study, professional members were sent a link to a confidential online survey questionnaire in a secure database under the researcher's name with an online cloud-based company. The privacy and confidentiality standards were detailed in both French and English and each respondent was required to sign an explicit consent statement before proceeding with the questionnaire. Respondents had the option to elect to complete the same questionnaire through a teleconference. There were 26 semistructured open-ended questions on perceived leadership attributes and skills, direct experiences, emergency preparedness, future scenarios, systemic performance, technology and coalitions. Table II highlights some of the salient study questions of the semi-structured interviews, using the WSR-Li construct.

\subsection{Study sample and response}

A total of 103 key informants were sent invitations to participate and complete the research instrument online or, as in seven cases, through a teleconference interview with the researcher within the study time limit. In total, 17 online questionnaires had negligible responses and were dropped from the study. The response rate was 83.5 percent with 86 key informants representing 81 organizations across Canada, including two from the USA. These included leaders from: 16 Federal government agencies; 17 Provincial government and regional health authorities; and 16 municipal government and first responder units. They also included 14 private consulting firms involved with emergency systems; 13 health care facilities; and five national professional associations. Of the total respondents, 89 percent were senior leaders with ten or more years of experience. Moreover, there were 28 health professionals, 15 government officials, 14 fire and rescue officers, 11 services care providers, ten military officers, four social workers and four information system professionals - all with relevant emergency management experience. Of the seven telephone interviews conducted with the same questionnaire, the researcher made detailed notes and verbally repeated the key points to the interviewee to clarify any responses.

\subsection{Grounded theory methodology}

This study deploys grounded theory and thematic analytical approaches with the conceptual space of the generic WSR-Li model, proposed by Zhu (2002). The theoretical 


\section{WSR-Li ${ }^{\text {a }}$ dimensions}

Transactional resources (wuli)

Relational capital (shili)

Transactional processes (renli)

Transformational processes (renli)

Note: ${ }^{\mathrm{a} Z h u}(2001,2002)$
Sample thematic questions

List the accessibility and availability resource challenges in emergency services

Describe the context of emergency service systems in which you work Describe critical emergency encounters you have personally experienced Describe up to five performance challenges encountered

Describe key emergency services systems lessons you have learnt through experiences

Comment on the extent to which the emergency management systems work effectively

List five emergency events that will threaten your community over the next 20 years

Indicate which emergency plans your organization currently has in place Indicate whether your organization actively tests and conducts simulations annually

Comment on the level of emergency preparedness in your organization Identify key catalysts and inhibitors to emergency services systems evolution Comment on up to three barriers to collaboration in emergency services systems

List and comment on the best leadership practices that promote systems collaboration

Describe critical leadership qualities in effective emergency management systems

List technological developments you foresee over the next 20 years Comment on your vision of technological changes and its impact on future emergency services systems
Table II.

Sample of thematic questions of

key informant study, using the WSR-Li paradigm ${ }^{\mathrm{a}}$

and analytical results produced an integrated systemic paradigm that sheds light on multidimensional transformational emergency leadership. The emergent theoretical construct is the theory of transcendent transformational emergency leadership.

Grounded theory is an inductive methodology, whereby theory is generated from systematic research. As a complex iterative process, it begins with generative questions posed to key informants. In this study, qualitative techniques of key informant analysis generated a wealth of textual data from which emerged conceptual categories. Using open-ended online questionnaires and structured interviews, the key informants provided textual descriptions of their professional experiences and perceptions of emergency leadership challenges. This open-ended approach evoked responses that were meaningful and particularly salient to each key informant. Furthermore, it produced an array of results that were explanatory, textually rich and often unanticipated.

In developing core theoretical concepts, the analytical processes included coding, memoing and integrating. In the coding process, qualitative data from the key informants was noted, analyzed, categorized into themes related to the initial core concept of emergency leadership. During this coding process, repeated concepts developed into substantive codes, which heralded the initial steps in forming new theory. Through memoing processes, the thoughts and ideas were recorded, as they evolved and developed with time.

In the integrative process, transformational emergency leadership emerged as a thematic core category, within which other codes became dimensions. 
IJES

5,1

24

These dimensions included: relational capital; transactional capital; transactional processes; transformational processes; and transcendental process skills. The final emerging theoretical code that best organized all substantive codes became transcendent transformational emergency leadership.

This resulting theory is grounded in the observations of key informants using the WSR-Li paradigm as a lens into the domain of emergency services leadership. This emergent theory of transcendent transformational emergency leadership is grounded in those dimensions that contribute significantly to enhancing performance outcomes in emergency management systems. The basic premise of this theory is that for transformational emergency leadership to be fully effective, it should be both transformational and transcendent. Aside from the multi-dimensional optics of the WSR-Li model, it includes a transcendental dimension that incorporates both transformational changes within governance organizations and inter-sectorial agents.

\section{Study results}

This qualitative study indicated key informant agreement on emergency leadership attributes and competencies. Moreover, the key informants identified 12 key strategic leadership challenges in emergency services systems. Table III highlights these through optics of the WSR-Li model. Moreover, this paper offers authentic direct quotes from select key informants. These direct quotes represent and reflect the deep passion of emergency leaders and their commitment for positive changes in emergency services systems.

Key emergency leadership challenges

Resource sufficiency and equitable distribution of care providers, emergency supply resources and financial resources Sharing of critical emergency information through effective telecommunication resources

Effective relational capital across professional disciplines across emergency services systems (horizontal integration)

Effective relational capital with governing bodies

(vertical integration)

Effective relational capital with the private technological sector

(inter-sectorial integration)

Effective and efficient operational management of emergency resources

Knowledge diffusion of emergency informatics, strategic logistics, performance management and systems engineering Effective collaboration networks and strategic coalitions Effective transformational leadership skills

Effective change management and promotion of

Table III.

Salient emergency leadership challenges of key informant study through the WRS-Li optic and beyond (Zhu, 2001) innovative technologies

Effective transformational leadership within governing authorities

Effective relational capital between intergovernmental authorities nationally and internationally

Note: ${ }^{\mathrm{a}} \mathrm{Zhu}(2001,2002)$

\section{WSR-Li}

Transactional processes (wuli) ${ }^{a}$ :

Resource sufficiency

Resource equity

Information resource sharing

Relational capital (shili) ${ }^{a}$ :

Horizontal integration

Vertical integration

Inter-sectorial integration

Transactional processes (renli) ${ }^{a}$ :

Efficiency

Effectiveness

Performance excellence

Transformational processes (renli) :

Strategic collaboration

Transformational leadership

Change management

Innovation

Transcendental forces:

Effective governance

Intergovernmental integration

Inter-sectorial 


\subsection{Emergency leadership attributes and competencies}

A senior emergency planner with a provincial government postulated: "Leading by example from the front means that a visible champion is required with sufficient authority and power to make things happen with and outside their particular sphere of influence. They must wield enough influence to challenge and convince others to follow suit. They must have vision and perseverance."

Key informant stressed that emergency leaders should be altruistic, authentic, ethical and understanding of diverse multidisciplinary professional views. Key informants believed that leaders should possess strategic foresight and vision that is motivated by caring and compassion for their fellow human-beings. Indeed, a compelling caring vision and empathy that inspires and motivates others are hallmarks of emergency services leaders. They also felt that decisiveness and the ability to make tough decisions in "the heat of battle" was important, as was courage and equanimity. Key informants perceived systemic performance depends on effective emergency preparedness. In turn, they felt that leaders have to be effective strategists with competencies in emergency preparedness and planning. Expertise in threat analysis with probability estimations was deemed important in formulating effective emergency preparedness strategies. Such analysis was particularly relevant in the formulation of effective business continuity, emergency response and recovery plans, thus underscoring the literature (Hills, 2015; Rodríguez-Sánchez and Perea, 2015; Eyre and Brady, 2013).

\subsection{Transactional capital challenges}

One provincial government official commented: "It [the local disaster] was beyond anyone's experience and came on unexpectedly and viciously. The organization of communication was a significant challenge. As always, politics came into play and some key leaders were not visible to those having to make decisions at the front line. It seemed the leaders were jockeying for more 'air time' than concerned about effectiveness. Roles and responsibilities were not clear. We were flying by the seats of our pants. There was no one stepping up to the plate."

Key informants identified two key strategic leadership challenges associated with transactional capital (wuli). The first was to assure resource sufficiency and equitable distribution of care providers, emergency supplies supported by adequate financing across systems. Key informants recognized that appropriate and stable resources are essential for the effective operational performance and sustainability of emergency services systems. The second was to assure that vital emergency information was effectively shared across systems through integrated telecommunications infrastructures. Key informants acknowledged that resource and communication constraints hindered effective emergency operations, particularly in northern and rural regions of Canada. Frontline emergency professionals in those regions are often called to do more with less, sometimes at a cost of unnecessary loss of life and higher longterm care costs to the system. They underscored that unstable and limited public funds significantly impact on the access to and availability of critical operational emergency resources. This challenge in turn hindered the efficient and effective performance of emergency services systems.

\subsection{Relational capital challenges}

A mental health social worker cited a case of suicidality: "An individual with intent to complete suicide was assessed and taken to the hospital. The hospital refused the patient. 
IJES

5,1

The system did not work. Trust and communication were lacking. Professional respect was not in existence. The hospital reacted to its perceived resource shortage and not to the needs of the patient. A community development approach that enlists the professional in the development of the process, rather than having the process presented to them at the time of an emergency. This will require more training and involvement than currently in place."

Key informants recognized the ongoing leadership challenge of building and continuously promulgated relational capital of mutual trust and understanding across multi-disciplines and emergency organizations. Perceptual differences arise from diverse assumptions, motivations, pressures, priorities, processes and views of emergency professionals and organizations. These differences stand in the way of systemic communication and collaboration. Credible emergency leaders who focus on shared caring values, goals and common perspectives help overcome divergent views. These innate abilities help to foster credibility and trust that reinforce relational bonds between professionals in emergency services systems. Relational capital promotes joint collaboration efforts and reinforces horizontal and vertical integration throughout emergency services systems. It is essential to enhancing resilience and mitigating risks (Gibson and Tarrant, 2010). It is also central to efficient and effective preparedness for, response to and recovery from emergencies. In effect, relational capital promulgates performance excellence in emergency services and constitutes a key challenge of leadership. It is also of import in vertical integration within and across different levels of governing bodies, be they municipal, regional, national and international. Finally they felt that inter-sectorial trust and open communication with the private technological sector was an important leadership challenge.

\subsection{Transactional process challenges}

A hospital administrator maintained: "Emergency management is essentially a logistics problem and needs to be treated as such. We can learn a lot from airlines and aviation authorities. But none of this will solve the people issues, of course! That needs people working together regularly and getting to know one another, before all hell breaks loose."

Key informants maintained effective operational management of appropriate emergency resources through transactional processes remains an important leadership challenge. These processes include emergency care processes, resource sharing, and knowledge creation and performance management within systems. Indeed, the effective deployment of critical care providers, resources and supplies is of paramount importance. As another key challenge key informants felt that emergency leaders needed to extend their knowledge and competencies to include emergency informatics, strategic logistics, performance management and systems engineering. The critical role of telecommunications, systems interoperability and technological innovations compels that leaders understand emergency informatics. Knowledge of strategic logistics is instrumental in forging effective strategies that assure timely access to vital emergency resources and supply chains (Andreoni and Miola, 2015) in concert with governing bodies, the military and private sector. Finally, key informants also underscored the need for performance management through the application of systems engineering to enhance systemic efficiency and effectiveness Such techniques include activity-based costing, benchmarking, process analysis and reengineering, lean design, root cause analysis and simulations. 


\subsection{Transformational processes challenges}

A senior military health official posited: "The Canadian Forces own the $14^{\text {th }}$ health system paradigm that exists in Canada. As we must maintain a pan-Canadian perspective in all we do, I have to define my community as the Canadian Forces geographically located across Canada and throughout the world. Communication of clear concise direction that can be interpreted and applied at a regional level, attention to regionally specific issues and respect and value of the input of multiple health care providers are critical to the success of our system."

A senior military officer in health care wrote: "Create a sense of urgency. All parties must understand that it is crucial to recognize, prepare for, plan and understand what faces them."

Key informants identified the creation of effective collaborative networks is an ongoing important leadership challenge in emergency services systems. Indeed, effective collaboration requires leadership cogent inter-organizational coalitions across multiple jurisdictional authorities regionally, nationally and internationally. Key informants also recognized the challenge of developing transformational leadership qualities of high adaptability who could work effectively with the myriad of emergency professionals and disciplines. Indeed, competencies in change management, conflict resolution, effective decision-making, negotiation skills and strategic thinking were deemed ongoing challenges. These transformational skills allow leaders to become effective change agents. They remain crucial ingredients to forge collaborating networks of diverse emergency professionals and multiple stakeholders. Another leadership challenge was the ability to forge positive bonds with all levels of governing authorities to promote positive systemic changes. Strategic partnerships with the private technological sector as a means to diffuse innovative technologies within the system was also viewed as a key strategic leadership challenge.

\section{Discussion}

There are six potential implications proposed from this emergency leadership study. These include: emerging transcendent transformations; integral caring leadership; inter-sectorial collaborative networks; adaptive integrative learning; the theory of transcendent transformational emergency leadership; and future emergency services systems research.

\subsection{Toward transcendental transformations}

A senior fire chief stated: "High level emergency public sector managers should take ownership of these [emergency] issues stressing the necessity for such programs. The public is generally complacent about emergency management and require a trusted individual to get the message out."

A senior provincial government official stated: "The governments at a national, provincial and municipal levels must work together to more clearly define roles and accountabilities toward planning response and recovery in disaster or emergency situations."

Key informants acknowledged the need for more relational capital, increase emergency resources and strengthen transformational leadership as emergency services systems evolve. In doing so, they recognized that the Realpolitik of socio-political and economic environments present ongoing systemic constraints and challenges. The nexus of consensus among emergency leaders appears to suggest that there is an additional supra-dimension of renli in the context of emergency services systems. 
IJES

5,1

This transcendental dimension points to transformational leadership within public governance systems. In Canada, public governance systems determine financing levels and resource allocation that shapes the strategic direction of emergency services systems. The proactive engagement and support of governing authorities is key to effective strategic collaborative networks and systemic performance. Cogent transformational leadership in public governance constitutes an essential "transcendental" dimension that impacts systemic effectiveness regionally, nationally and internationally. Whether through governance legislation and regulations, public financing, technological standards and knowledge management, ultimately public governing forces are important in the positive transformation of emergency services systems. Thus, transformational leaders in emergency services systems are often limited and stymied in what changes they can effect, unless there is also transformational leadership within the public governance domain ipso facto.

\subsection{Toward integral caring leadership}

A (recently decedent [...] an untimely sudden death) hospital administrator stated: "Disaster planning must be a key CEO responsibility, rather than an assignment for a junior staff member of an accreditation committee. Time!"

It would appear that transformational leadership is the nexus of performance excellence. Transformational leadership with its focus on engaging communities of professionals and organizations fosters collaboration toward the common visions in emergency services systems. It focusses on synergistic decision-making in highly complex, dynamic and uncertain contextual environments of emergencies. Such environments will continue to require competencies of coalition building, flexibility, foresight and vision, innovation, and negotiation in orchestrating systemic processes and fostering systemic performance excellence. In essence, transformational emergency leadership would appear to be essential in mitigating the impacts of mass emergencies, disasters and catastrophes. Moreover, such leadership should always be based on caring, compassionate and humane values that preserve and uphold health, well-being and communal integrity. However, dynamic socio-cultural interactions, increasing global threats and vulnerabilities technological growth and innovations and might compel a revisiting of leadership concepts in the future. In particular, integral leadership with its multi-dimensional and holistic view of humans, technologies, ecologies and systems invites scrutiny of emerging modalities of leadership (Wilber, 2000). Although critical re-examination of current leadership paradigms in light of twenty-first century dictums might appear to be in order, the caring values must always remain integral.

\subsection{Toward inter-sectorial collaborative networks}

A senior provincial government official stated: "The greatest barrier is one of (sectorial) culture. In the private sector, poor performance is not tolerated. In the public sector, poor performance is. Very few were dismissed for poor performance during the SARS epidemic that cost Toronto approximately $\$ 1$ billion in lost revenue. If a business in the private sector lost $\$ 1$ billion, there would be significant accountability implications."

The implementation of high-reliability emergency organizations are one of the innovative strategies that emergency leaders as change agents may promulgate (Velev and Zlateva, 2011). Continuous learning, systemic improvements and adaptability are 
the hallmarks of such organizations that seek to prevent and mitigate the impact of emergency events. Transformational leaders are potential catalysts to transform systems through a panoply of promising technologies that might redefine the work of future emergency professionals. Such innovations appear to include: autonomic computers; big-data storage capacities; driverless emergency vehicles; drones; holographic applications; intelligent expert technologies; nanotechnology; robotics; sensor technologies; tele-surgery and virtualization technologies. Investigation into the potential application of these technologies will require inter-sectorial collaboration between the public emergency and private sectors. For this to happen, emergency leaders must focus on building relational capital with the private technological sector. The transgenic forces of governing organizations may be catalysts to facilitate these inter-sectorial coalitions, as innovations diffuse through societies.

\subsection{Toward adaptive integrative learning}

An emergency medical social worker reflected: "Partnerships and integration of vision and processes between IT professionals and health care staff in emergency rooms, police, paramedics and home care services are the key ingredients to the successful delivery of medical care to patients. IT plays a key support role for linking these services together by assuring clear and effective communication by all parties who are delivering the care to the patient."

Adaptive and continuous learning of emergency leaders remains a challenge. Transformational leaders need to have a sound grounding in the operations of emergency services systems, as well as on the socio-political contexts in which they take form. A knowledge of strategic management with its emphasis on strategy formulation and execution is relevant. Moreover, emergency informatics, environmental health, health sciences, strategic logistics and systems engineering are also important. Post-secondary and graduate training programs and professional certification in emergency leadership might be avenues to explore. Continuous learning opportunities should be available to all emergency service professionals, be they emergency planners, fire and rescue officers, paramedics, medical specialists, mental health specialists, emergency nurses, rehabilitation specialists or emergency social workers. Emergency leadership programs should ideally require mandatory exposure to a range of emergencies in collaboration with a panoply of emergency professionals across the system. Aside from new pertinent knowledge, intensive experiential learning and testing is also important. Rigorous simulations and multi-professional intensive exercises based on airline pilot or military pedagogical models might be in order. The judicious selection of candidates and group cohorts is also important. Proven expertise and personal leadership attributes might be important criteria for entrance to higher education for future leaders in emergency services systems.

\subsection{Toward the theory of transcendent transformational emergency leadership}

A (recently retired) hospital administrator stated: "We need someone with the qualities of a General Eisenhower or General Patton to take command of implementing IT [Information Technology] collaboration. This leader will need legislative authority so that they can deal appropriately with naysayers and foot-draggers. The command and control structure of the military [...] Nothing short of that will work!"

Consonant with a grounded theory approach in this study, new theory emerged that had its substance in those dimensions that contribute significantly to enhancing 
IJES

5,1

performance and positive clinical outcomes in emergency management systems. This is the theory of transcendent transformational emergency leadership. Its basic premise is that for transformational emergency leadership to be fully effective, it should be both transformational and transcendental. Aside from the multi-dimensional optics of the WSR-Li model, the theory posits that this transcendental dimension that incorporates both transformational changes within governance organizations and inter-sectorial agents. This paradigm then goes beyond and transcends to include this added dimension. It is essentially the nexus of emergency leadership that underscoring the importance of transcendental transformations integrated caring values, inter-sectorial systemic collaboration and adaptive integrative learning. This theory of transcendent transformational emergency leadership is posited to hold promise in understanding evolving emergency services systems of the future.

\subsection{Toward future emergency services systems research}

Qualitative research using grounded theory and key informant approaches hold promise for examining perceptions of emergency leaders and professionals on a gamut of potential areas. These may include studies in: disaster management and recovery, emergency informatics, emergency intelligent systems, emergency refugee systems, emergency supply chains, first-response systems, international collaborative networks, medical command operations, incident patient-relationship management, posttraumatic stress disorders and robotic systems. Delphi qualitative studies into these areas also hold investigative potential. Emergency leadership studies using innovative models in different socio-cultural and socio-political contexts hold promise. For example, research investigation of integral leadership models might be of great import in understanding international emergency services systems. There is also an important role of current and future global research centers that could promulgate collaborative networks of international researchers in emergency service systems. The increase of the numbers and magnitude of future emergency events in this century will no doubt compel further emergency services research to prevent their re-occurrence or mitigate their deleterious impacts on victims and communities. Emergency research is not an end in itself, but promises to elucidate ways to effectively deploy new emergency knowledge and innovative technologies for the betterment of humankind.

\section{Conclusion}

Emergency leadership is the lodestar of ever-evolving emergency services systems. Relational capital builds viable strategic collaborations thrive horizontally and vertically in the system. From Zhu's paradigm, systemic efficiencies and effectiveness depend on leaders with considerable relational capital and who exercise transformational leadership. This study focussed on the perceptions of emergency services leaders engaged in cultures where public service and governance are profound and cogent social value. Furthermore, it would appear that the transformational base rests where transactional power is concentrated. The most effective emergency services systems are likely the ones where leaders have investing in fostered cogent and stable collaboration horizontally and vertically across emergency services systems and with governing authorities, be they regional, national and/or international.

The theory of transcendent transformational emergency leadership is posited to suggest future directions that potentially leverage, sustain and transmute emergency services systems for the public benefit. It is the strength and quality of governance 
transformational leadership that provide the transcendental energy that essentially drives improvements in emergency services systems. Transcendental governance forces appear to be particularly relevant in nations, such as Canada, that adhere to cogent public service and social governance values. It is in these values that emergency services systems are substantiated and take form. It is the strength and quality of governance leadership that provide the transformational and "transgenic" energy, which drives improvements in emergency services systems. The universe of emergency services systems is fraught with complex competing priorities and challenges in a world with converging international values. Transformational emergency leadership with its emphasis on innovative changes, while upholding strong caring and public service values will continue to be of relevance. The frequency and magnitude of emergency events will undoubtedly increase. Global demographic changes and socio-political chaos and turmoil will likely increase exposure to growing range of threats in vulnerable environments nationally and internationally. Emergency preparedness and proactive scenario analysis in collaboration with emergency services authorities underscore that communities must ever be at ready for potential threats. Ultimately, it is the public themselves who will judge whether emergency services systems have met performance expectations and performance. They will hold leaders to account come the time of ultimate tests of mass emergencies, disasters and catastrophes. They must not be found wanting. No longer do emergency events end at the door of hospital emergency departments. Rather they find closure when communities, victims, and emergency professionals and communities have fully physically, emotionally and socially recovered from the ordeals experienced (Caro, 2015). Internationally, what with emergency resource constraints, limited political will and wavering public support, sustainable emergency services systems will continue to require cogent transformational leadership. Leadership in emergency services systems will be crucial in the future evolution of effective emergency critical systems nationally and internationally. Ultimately, all this is for the common benefit of humankind in face of the ravages regional, national and international emergency scenarios.

\section{References}

Andreoni, V. and Miola, A. (2015), "Climate change and supply-chain vulnerability: methodologies for resilience and impacts quantification”, International Journal of Emergency Services, Vol. 4 No. 1, pp. 6-26, available at: http//dx.doi.org/10.1108/IJES-092014-0012

Avolio, B.J. and Gardner, W.L. (2005), "Authentic leadership development: getting to the root of positive forms of leadership”, Leadership Quarterly, Vol. 16 No. 3, pp. 315-338, available at: http//dx.doi.org/10.1016/j.leaqua.2005.03.001

Bass, B.M. and Bass, R. (2009), The Bass Handbook of Leadership: Theory, Research \& Managerial Applications, The Free Press, New York, NY.

Bass, B.M. and Steidlmeier, P. (1999), "Ethics, character and authentic leadership behaviour", The Leadership Quarterly, Vol. 10 No. 2, pp. 181-217.

Burstrom, L., Starrin, B., Engstrom, M. and Thulesius, H. (2013), "Waiting management at the emergency department - a grounded theory study", BMC Health Services Research, Vol. 13 No. 1, pp. 95, available at: http//dx.doi.org/10.1186/1472-6963-13-95

Caro, D.H.J. (2015), "Code red: towards authentic transformational leadership of emergency management systems", Journal of Hospital Administration, Vol. 4 No. 5, pp. 1-12, available at: http//dx.doi.org/10.5430/jha.v4n5p 
IJES

5,1

32

Charman, S. (2015), "Crossing cultural boundaries: Reconsidering the cultural characteristics of police officers and ambulance staff", International Journal of Emergency Services, Vol. 4 No. 2, pp. 158-176, available at: http//dx.doi.org/10.1108/IJES-07-2014-0011

Charmas, K. (2014), Constructing Grounded Theory, Sage Publications, London.

De Florio, V. (2014), "Quality indicators for collective systems resilience”, Emergence: Complexity and Organization, Vol. 16 No. 3, pp. 65-104.

Eyre, A. and Brady, K. (2013), "Addressing psychosocial and community recovery in emergency management”, International Journal of Emergency Services, Vol. 2 No. 1, pp. 60-72, available at: http//dx.doi.org/10.1108/IJES-09-2012-0037

Gibson, C.A. and Tarrant, M. (2010), "A 'conceptual models' approach to organisational resilience”, The Australian Journal of Emergency Management, Vol. 25 No. 2, pp. 6-12.

Hayes, P.A.J. and Omodei, M.M. (2011), "Managing emergencies: key competencies for incident management teams", Australian and New Zealand Journal of Organizational Psychology, Vol. 4, April, pp. 1-10, available at: http//dx.doi.org/10.1375/ajop.4.1.1

Hills, M. (2015), “Assuring organisational resilience with lean scenario-driven exercises", International Journal of Emergency Services, Vol. 4 No. 1, pp. 37-49, available at: http//dx. doi.org/10.1108/IJES-09-2014-0019

Hopia, H. and Hakala, A. (2015), "Finnish social and health care professionals' perspective of the future", International Journal of Healthcare, Vol. 2 No. 1, pp. 12-20, available at: http://dx. doi.org/10.5430/ijh.v2n1p12

Karaca, H., Kapucu, N. and Van Wart, M. (2012), "Examining the role of transformational leadership in emergency management: the case of FEMA", Risks, Hazards \& Crisis in Public Policy, Vol. 3 No. 3, pp. 19-37, available at: http://dx.doi.org/10.1002/rhc3.10

Larsson, G. and Eid, J. (2012), “An idea paper on leadership theory integration”, Management Research Review, Vol. 35 No. 3, pp. 177-191, available at: http://dx.doi.org/10.1108/ 01409171211210109

Larsson, G. and Hyllengren, P. (2013), "Contextual influences on leadership in emergency type organisations", International Journal of Organizational Analysis, Vol. 21 No. 1, pp. 19-37, available at: http://dx.doi.org/10.1108/19348831311322515

Launder, D. and Perry, C. (2014), "A study identifying factors influencing decision making in dynamic emergencies like urban fire and rescue settings", International Journal of Emergency Services, Vol. 3 No. 2, pp. 144-161, available at: http//dx.doi.org/10.1108/IJES-062013-0016

Leggio, W.J. Jr (2014), "The state of leadership education in emergency medical services: a multinational qualitative study", Prehospital Disaster Medicine, Vol. 29 No. 5, pp. 1-6, available at: http://dx.doi.org/10.1017/S1049023X14000867

Ma, A.M.J. and Osula, B. (2011), "The Tao of complex adaptive systems (CAS)", Chinese Management Studies, Vol. 5 No. 1, pp. 94-110, available at: http://dx.doi.org/10.1108/ 17506141111118480

Moe, T.L. (2012), "Aiming for resilience and adaptation in managing environment: an emerging environmental and emergency leadership in the twenty-first century", International Journal of Disaster Resilience in the Built Environment, Vol. 3 No. 1, pp. 42-51, available at: http://dx. doi.org/10.1108/17595901211201123

Obolensky, N. (2014), Complex Adaptive Leadership: Embracing Paradox and Uncertainty, Gower Publishing, Farnham.

Osborna, R.N. and Marion, R. (2009), "Contextual leadership, transformational leadership and the performance of international innovation seeking alliances", The Leadership Quarterly, Vol. 20 No. 2, pp. 191-206. 
Phipps, S.T.A. and Prieto, L.C. (2011), "The influence of personality factors on transformational leadership: exploring the moderating role of political skill", International Journal of Leadership Studies, Vol. 6 No. 3, pp. 430-447.

Price, T.L. (2003), "The ethics of authentic transformational leadership", The Leadership Quarterly, Vol. 14 No. 1, pp. 67-81.

Quinn, R., Faerman, S.R., Thompson, M.P. and St. Clair, L.S. (2007), Becoming a Master Manager: A Competing Values Approach, John Wiley \& Sons, New York, NY.

Rimstad, R. and Sollid, S.M.J. (2015), "A retrospective observational study of medical incident command and decision-making in the 2011 Oslo bombing", International Journal of Emergency Medicine, Vol. 8 No. 4, pp. 1-10, available at: http//dx.doi.org/10.1186/s12245015-0052-9

Rodríguez-Sánchez, A.M. and Perea, M.V. (2015), "The secret of organisation success: a revision on organisational and team resilience", International Journal of Emergency Services, Vol. 4 No. 1, pp. 27-36, available at: http//dx.doi.org/10.1108/IJES-09-2014-0018

Seidel, S. and Urquhart, C. (2013), "On emergence and forcing in information systems grounded theory studies: the case of Strauss and Corbin”, Journal of Information Technology, Vol. 28 No. 3, pp. 237-260, available at: http//dx.doi.org/10.1057/jit.2013.17

Velev, D. and Zlateva, P. (2011), "Innovative approach for designing an emergency risk management system for natural disasters", Journal of Innovation Management and Technology, Vol. 2 No. 5, pp. 407-413.

Wilber, K. (2000), A Theory of Everything: An Integral Vision for Business, Politics, Science, and Spirituality, Shambhala Publications, Boston, MA.

Zhu, Z. (2001), "Towards an integrating programme for information systems design: an oriental case", Journal of Information Management, Vol. 21 No. 1, pp. 69-90.

Zhu, Z. (2002), "Evaluating contingency approaches to information systems design", Journal of Information Management, Vol. 22 No. 5, pp. 343-356.

\section{Further reading}

Moerschell, L. and Lao, T.M. (2012), "Igniting the leadership spark: an exploration of decision making and punctuated change", Emergence: Complex Organizations, Vol. 14 No. 2, pp. 54-68.

Urby, H. and McEntire, D.A. (2015), "Emergency managers as change agents: recognizing the value of management, leadership, and strategic management in the disaster profession", Journal of Emergency Management, Vol. 13 No. 1, pp. 37-51, available at: http://dx.doi.org/ 10.5055/jem.2015.0216

\section{Corresponding author}

Denis Caro can be contacted at: drcaro@uottawa.ca

For instructions on how to order reprints of this article, please visit our website: 